NBER WORKING PAPER SERIES

\title{
BONES, BOMBS AND BREAK POINTS: THE GEOGRAPHY OF ECONOMIC ACTIVITY
}

\author{
Donald R. Davis \\ David E. Weinstein \\ Working Paper 8517 \\ http://www.nber.org/papers/w8517
NATIONAL BUREAU OF ECONOMIC RESEARCH
1050 Massachusetts Avenue
Cambridge, MA 02138 \\ October 2001
}

The authors want to especially thank Mary Berry, Wayne Farris, and Hiroshi Kito who helped us enormously in obtaining and understanding the historical demographic data. While their help was instrumental, all remaining errors are the responsibility of the authors. Kazuko Shirono gave us tremendous help with the archival and data construction aspects of the paper. Joshua Greenfield also helped input the bombing data. Weinstein wants to also thank the Japan Society for the Promotion of Science for funding part of this research, and Seiichi Katayama for providing him with research space and access to the Kobe University library. The views expressed herein are those of the authors and not necessarily those of the National Bureau of Economic Research.

(C) 2001 by Donald R. Davis and David E. Weinstein. All rights reserved. Short sections of text, not to exceed two paragraphs, may be quoted without explicit permission provided that full credit, including (C) notice, is given to the source. 
Bones, Bombs and Break Points: The Geography of Economic Activity

Donald R. Davis and David E. Weinstein

NBER Working Paper No. 8517

October 2001

JEL No. F1, R1, J1

\begin{abstract}
We consider the distribution of economic activity within a country in light of three leading theories - increasing returns, random growth, and locational fundamentals. To do so, we examine the distribution of regional population in Japan from the Stone Age to the modern era. We also consider the Allied bombing of Japanese cities in WWII as a shock to relative city sizes. Our results support a hybrid theory in which locational fundamentals establish the spatial pattern of relative regional densities, but increasing returns may help to determine the degree of spatial differentiation. One implication of these results is that even large temporary shocks to urban areas have no long-run impact on city size.
\end{abstract}

Donald R. Davis

Department of Economics

Columbia University

1038 Int'1 Affairs Building

420 West $118^{\text {th }}$ St.

New York, NY 10027

and NBER

drd28@columbia.edu
David E. Weinstein

Department of Economics

Columbia University

420 West $118^{\text {th }}$ St.

MC 3308

New York, NY 10027

and NBER

dew35@columbia.edu 


\section{Bones, Bombs and Break Points The Geography of Economic Activity}

\section{Introduction}

In the last decade, the field of economic geography has enjoyed a renaissance. ${ }_{\text {The }}$ central question in this literature is how to explain the distribution of economic activity across space - across countries of the world, across regions within a country, and across cities. Three principal theoretical approaches have emerged, which may be termed increasing returns; random growth; and locational fundamentals. The increasing returns theories posit that advantages of size may arise from knowledge spillovers, labor market pooling, or the advantages of proximity for both suppliers and demanders in a world of costly trade. In this approach, a distribution of city sizes may arise from technological characteristics of individual industries (Henderson 1974) or from the tacit competition among locations for mobile factors of production (Krugman 1991). The random growth theory (Simon 1955, Gabaix 1999) holds that a distribution of cities of quite different sizes emerges from very simple stochastic processes. One large advantage of this approach is that it is able to explain a key empirical regularity known as Zipf's Law regarding the distribution of city sizes that, to date, the increasing returns theories cannot explain. The locational fundamentals theory (Krugman 1996) may be thought of as a variant of the random growth theory. Instead of city growth itself being random, it is fundamental economic characteristics of locations that are random. If we posit that these characteristics are distributed according to the same process as in Gabaix (1999), then the locational fundamentals theory also can account for Zipf's Law. However, in contrast to the random growth theory, the locational

\footnotetext{
${ }^{1}$ Paul Krugman has argued that the study of the spatial location of economic activity should assume a stature in the profession equal to one of the flagship fields such as international trade [Paul R. Krugman 1995]. A new Journal of Economic Geography has been founded. While demurring from some of Krugman's strongest claims, J. Peter Neary, writing a review article in the Journal of Economic Literature, declares "New economic geography has come of age" [Neary 2001, p. 536].
} 
fundamentals story predicts that the size of specific locations should be robust even to large temporary shocks.

In this paper, we will examine these three theories empirically. A few key questions emerge. How important are scale economies in explaining the degree of spatial concentration of economic activity? ${ }^{1}$ The premise that we work from is that the forces of increasing returns must be vastly stronger in a modern, knowledge-based economy than in more primitive, agricultural or pre-agricultural, economies. To investigate this, we employ a unique data set on Japanese regional population over the past 8,000 years. The answer that we provide has two parts. First, for the 8,000 years in our data set, there has always been a great deal of variation in measures of regional population density. This alone suggests that important factors other than increasing returns help to explain the variation in the density of economic activity. Second, there has been a notable rise in concentration in the last century as Japan industrialized and become ever more integrated into the world economy. This suggests that the increasing returns theories may help to account for the rise in dispersion.

The same data set can be employed to address a second key question. Over tens, hundreds or thousands of years, how much persistence should we expect in the identity of the most densely settled regions? The increasing returns theories do not answer with a single voice. Insofar as the size distribution is tied to technological characteristics of particular industries, then

\footnotetext{
${ }^{2}$ It is tempting to say that one of the main things missing from the new economic geography is geography! This would be a bit too strong, since Fujita and Mori (1996), for example have a very nice paper on the role of ports. More typical, though, is a tendency to focus almost exclusively on factors with no real geographical counterpart, as in the survey by Fujita and Thisse (1996): "The main reasons for the formation of economic clusters involving firms and/or households are analyzed: (i) externalities under perfect competition; (ii) increasing returns under monopolistic competition; and (iii) spatial competition under strategic interaction."

${ }^{3}$ Indeed, FKV have staked strong claims for the IR theories: "[T] he dramatic spatial unevenness of the real economy - the disparities between densely populated manufacturing belts and thinly populated farm belts, between congested cities and desolate rural areas; the spectacular concentration of particular industries in Silicon Valleys and Hollywoods - is surely the result not of inherent differences among locations but of some set of cumulative processes, necessarily involving some form of increasing returns, whereby geographic concentration can be selfreinforcing." [FKV, p. 2].
} 
as we move from hunter-gatherer societies, to agriculture-based societies, through feudalism, into and out of autarky, and finally to a modern industrial economy, one might guess that there would be radical shifts over time in which are the densely populated regions. On the other hand, an important strand within the increasing returns theories has stressed the role of path dependence (David 2000, Krugman 1991b). An early start in one location provides that site with advantages at each succeeding stage of locational competition. The random growth theory is likewise consistent with correlation across long stretches of time in the spatial density of particular locations so long as the variance of growth rates is not too large relative to the mean growth rate. The clearest prediction comes from the locational fundamentals theory, which would hold that many of the crucial characteristics for locations have changed little over time even if the economic meaning may have evolved. For example, there are advantages of being near a river, on the coast, on a plain instead of a mountain or desert, etc. Our empirical results strongly confirm that there is a great deal of persistence across time in which are the densely settled regions. For the increasing returns theory, this would stress the importance of path dependence. For the random growth theory, this requires that the variance of growth have not been too high. However, we believe that this persistence arises most naturally from the locational fundamentals story and suggests this may be an important component of a complete answer.

Finally, the theories have quite distinct stories to tell about how the distribution of city sizes will be affected by a powerful, but temporary, shock. The increasing returns literature, as noted earlier, has given a prominent role to path dependence as well as to the possibility of catastrophes in which even small shocks may give rise to large and irreversible structural 


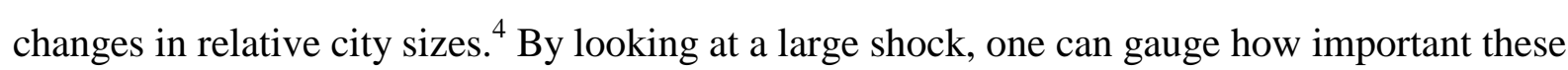
theoretical possibilities of catastrophic spatial change are in practice. The pure random growth theory predicts that growth follows a random walk. All shocks have permanent effects. By contrast, the locational fundamentals story holds that so long as the shock is purely temporary, even strong shocks should shortly be reversed, as the advantages of the particular locations reassert themselves in relatively rapid growth rates on the path to recovery.

The particular experiment that we consider is the Allied bombing of Japanese cities during World War II. This is one of the most powerful shocks to relative city sizes that the world has ever experienced. We find that, in the wake of the destruction, there was an extremely powerful recovery. Most cities returned to their relative position in the distribution of city sizes within about fifteen years. This strikes most strongly at the random growth theory, which predicts no reversion to the prior path. For the increasing returns theory, this suggests that however appealing the theoretical possibility of spatial catastrophes, in practice the distribution of city sizes seems to be highly robust to temporary shocks even of great magnitude. Finally, the reversion to the prior growth path would seem to be a strong confirmation of a locational fundamentals theory.

In sum, our experiments are very problematic for the pure random growth theory. While this theory provides a foundation for understanding Zipf's Law, it fails utterly to predict the great robustness of particular locations to strong temporary shocks. For the increasing returns theory, the message is more nuanced. There has long been a great deal of spatial dispersion of economic activity, so increasing returns is not necessary to explain this. Nonetheless, in the last century there has been a substantial rise in the degree of spatial dispersion, and this well might be

\footnotetext{
${ }^{4}$ For example, Krugman (1998) writes: "The new work is highly suggestive, particularly in indicating how historical accident can shape economic geography, and how gradual changes in underlying parameters can produce discontinuous change in spatial structure."
} 
accounted for by increasing returns. The emphasis within the increasing returns literature on the possibility of spatial catastrophes in the distribution of city sizes seems to be of greater interest theoretically than empirically. Finally, the locational fundamentals theory fares quite well in our empirical investigations. It has an advantage over the increasing returns theory in that it provides a simple account of Zipf's Law. It can provide a consistent story about why there has been a great deal of spatial dispersion over long stretches of time. It can explain why there has been a great deal of persistence in which regions are most densely settled. And it can explain why specific locations are highly robust even to temporary shocks of great magnitude. The one weakness is that it does not provide a reason why the degree of concentration in Japan should have increased in the last century.

These considerations lead us to believe that the most promising direction for research is to consider a hybrid theory in which locational fundamentals play a key role in establishing the basic pattern of relative regional densities and in which increasing returns plays a strong role in determining the degree of concentration.

\section{Bones: Archaeology, History and Economic Geography}

\section{A. The Data}

In this section, we examine 8,000 years of data on Japanese regions in order to address key questions concerning variation and persistence of regional population densities. Historically, how large has the variation in regional population density been and are there important changes over time? And how persistent is the identity of the regions that have been most densely settled? We then discuss the results in light of the three theories noted above. 
The data that we bring to bear is of two main types. ${ }_{\text {As we move back in time two }}$ millennia and more, one has access neither to regional accounts nor to population censuses. However, Koyama (1978) provides detailed data on the number of archaeological sites, including 28,013 from the Jomon period (-6,000 to -300$)$ and another 10,530 sites from the Yayoi period (-300 to 300). These have been divided according to the 46 modern prefectures in which they are located. We take a count of these archaeological sites for the respective periods as a proxy for the level of economic activity in the prefectures.

The second type of data is population. In order to provide a basis for taxation, Japan began censuses of population quite early. This was done at a regional level because of the substantial autonomy of local lords. Kito (1996) provides the best estimates of regional population for 68 provinces (kuni) for the period beginning in 725 and ending in 1872. In 1920 regional censuses began using a system based on 46 prefectures (ken), and this system continues through our most recent data for the year 1998. BOften we will find it convenient to work with data that allows a comparison across all of these periods of time. A quite close match between the data sets can be achieved when we aggregate up to 39 regions. Kito (1996) also provides estimates of total population of Japan for the Jomon and Yayoi periods.

We need to discuss the unit of analysis. A great deal of work on economic geography considers cities rather than regions as the unit of analysis. We do have data on cities, and we will discuss it, but this data extends back only to 1925. All of our earlier data concerns regions, which thus must be the unit of analysis. There are, nonetheless, good reasons why one might prefer the regional data. The first is that since the definition of a city always involves a threshold, even purely uniform growth of population in all locations may appear non-uniform because

\footnotetext{
${ }^{5}$ Details on data construction are discussed in Appendix I.

${ }^{6}$ The move to prefectures occurred earlier, but the 1920 census is the first to use these categories.
} 
populations may cross the threshold in some locations but not others. A second reason is that, especially over long stretches of time, the appropriate definition of cities changes. For example, areas that are considered core parts of modern Tokyo would not have been thought of as part of historical Tokyo (Edo). It is not at all clear how one should or could deal with such issues. Third, for some of our early periods, virtually all of the population lived outside of anything that in modern terms would be thought of as a city. Taken together, these factors suggest that the turn to regional data may be a necessity, but it is one with many virtues.

By focusing on regional data, one transformation becomes absolutely essential.

Differences in region sizes are large and the demarcation between regions does not always correspond to an obvious economic rationale. This suggests that we work not with the raw regional population, but instead with the population deflated by the regional area. This measure of regional population density will be the unit of analysis for this portion of our study. $\square$

One of the key reasons for turning to the historical data is that economies of the remote past look quite different from the modern economy. By examining such data, we are able to abstract from forces that we think are important today, but much less so in earlier times. Hence it is also important to have in mind the principal features of the earlier economies (as outlined in Table 1). Our earliest data on archaeological sites of the Jomon period (-6,000 to -300) takes us back to the Stone Age. The economy is based on hunting and gathering. There are no metal tools or agriculture, although there is evidence of pottery. The Yayoi period (-300 to 300$)$ is a revolutionary time, with the introduction of primitive forms of agriculture, metallurgy and some coins. As yet, there is neither writing nor cloth. Our next stop in history is the year 725 . A feudal regime had risen and we have the first population census. Writing is well developed and farming is widespread. The capital is in Nara. By 800 , the capital has moved to Kyoto and greater

\footnotetext{
${ }^{7}$ Rappaport and Sachs (2001) also focus on regional population densities in the U.S. for similar reasons.
} 
protection of peasant property rights has encouraged more widespread cultivation. The next century would see more extensive usage of metal farm tools, raising productivity. By 1150 , Japan was racked by instability and civil war, particularly in the North. By 1600, the reunification of Japan was complete and there is extensive trade and contact with the West. Japan is a major regional power. By the 1630s, however, Japan began more than two centuries of selfimposed isolation. By 1721, the capital moved to Tokyo and population movement became more restricted. Even as late as 1798, fully 80 percent of the population was farmers, about 6 percent nobility, with the remainder merchants and artisans. By the 1870s, Japan witnessed a civil war, the end of the Shogun's government, a jump from autarky to free trade, and the subsidized import of Western technology. This can be thought of as the very start of Japan's industrial revolution. By the 1920s, industrialization and the accompanying militarization are in full swing. Japan is a major exporter of silk and textiles. Nonetheless, approximately 50 percent of the work force is still composed of farmers. By 1998, of course, Japan is a highly industrialized society, with farmers now comprising only 5 percent of the population. Tokyo is one of the world's great cities with a population of 12 million. In sum, our data covers Japan from the Stone Age to the modern era.

\section{B. Population and Variation in Regional Density}

We begin by examining the evolution of the total population of Japan. The main features are developed in Table 1. Kito (1996) estimates that the population in Jomon period Japan would have been approximately 125,000; by 1998, it would fall just shy of 120 million. In short, our data encompasses a period in which Japanese population rises by a factor of nearly one thousand. If we restrict attention to the period for which we have censuses, i.e. from 725 to 1998 , the 
population rises from 4.5 million to nearly 120 million. That is, our census data encompasses a period in which total Japanese population rises by a factor greater than 25 . From the Jomon period through about 1721, the broad trend is substantial population growth. In large measure, this reflects the development of agriculture and its implements, extension of regions of cultivation, and establishment of institutions that encouraged investments in the land. For the next century and a half, through the 1870 s, there is very little population growth. In the next hundred and twenty years, through 1998, Japanese population would double twice over, rising from 30 to 120 million.

There are several measures one can give of variation in regional population density. A very coarse but simple measure is the share of population accounted for by the five most populous regions. This concentration was quite high, at 39 percent, in the Jomon period. This appears to reflect the fact that without agriculture, metal tools, or clothing, major sections of Japan were virtually uninhabitable. From here through the dawn of the twentieth century, the share of the five largest regions typically hovered around 20 percent, occasionally rising toward 30 percent. Remarkably, by the end of the twentieth century, the share of the five most populous regions would rise above 40 percent.

A second measure of regional variation is what may be termed the relative variance of log population density, which measures variance in proportional terms. To get this, first take logs of the regional population densities. For each period, this allows us to compute a variance of the $\log$ population densities. If we now normalize this by the same measure of variation for 1998, we get a measure that is above unity if the variation is greater in the historical period than in modern Japan and below unity in the reverse case.

\footnotetext{
${ }^{8}$ An advantage of using this measure over simply using the variance in population density is that the former is invariant to average density while the latter tends to rise with it. The reason for this is that as population, and hence
} 
A first observation is that regional population variation is substantially higher in the modern period than at all prior dates except the Jomon and Yayoi periods. Again, one reason there is so much variation in the Jomon and Yayoi periods is simply that the economies were so primitive that major sections of Japan were almost uninhabitable. A second observation is that all of the censuses from 700 to 1600 show a great deal of variation in regional population density typically two-thirds to three-fourths of the modern variation. Indeed an $F$-test reveals that we cannot reject the hypothesis that variance in regional population density in any year prior to 1721 was the same as the modern variance (at the 5 percent level). Interestingly, the data from 1721 through 1872 show, the closure of Japan seems to have been accompanied by a substantial reduction in regional population variation. A plausible reason is that eight out of the twelve densest regions in 1600 comprised port cities whose share of population declined markedly over this time period. ${ }^{9}$ Closure to trade probably dramatically reduced the value of locating in a port relative to remaining in farming. ${ }^{10}$ Finally, the re-opening of Japan and the development of the modern economy gave rise to a substantial increase in regional variation in population density.

We can also examine a third measure of variation in regional density, the Zipf coefficient. We have already noted, in reference to the random growth theory, that there is an empirical regularity known as Zipf's Law for Cities. To understand this, rank the cities by population and now take logs of both the rank of the city and of its population. Zipf's Law for Cities holds that a regression of the log rank against log population will have a slope of minus unity. Gabaix (1999) reports a slope of -1.004 for the United States and Rosen and Resnick (1980) report slopes for a variety of OECD countries, many of which are reasonably close to minus unity.

average density, rises, the same proportional density differences produce higher absolute variations in density. Since we wanted to sweep this effect out of the data, we calculate variance based on log population density.

${ }^{9}$ These were Chiba, Fukuoka, Kobe, Nagoya, Osaka, Tokyo, Yokkaichi, and Yokohama.

${ }^{10}$ Other policies may also have affected city sizes such as the construction of castle-towns, tax evasion in rural areas, and declining finances for samurai [See Hall (1968) and Hanley and Yamamura (1977)] 
In this context, the magnitude of the Zipf coefficient provides information about variation in regional density. If there were only trivial variation in regional population density, then the Zipf slope would be close to minus infinity. If virtually all of the population were clustered in a single region, the Zipf coefficient would be close to zero. Hence when the magnitude of the Zipf coefficient is small, the variation is large. Here we will report Zipf coefficients computed not on city populations but on regional population densities. As we will see, this transformation does little to disturb the basic relation.

One should not directly run Zipf-style regressions on historical data since the population data is surely measured with error. In order to obtain unbiased estimates, we need an instrument correlated with historical population data but not correlated with the measurement error in that survey. An obvious instrument that fits the need is modern population density, since it is strongly correlated with historical density but not with historical census errors. We therefore used density in 1998 as an instrument for earlier census data. We had a different problem with the Jomon and Yayoi data. Urban density in 1998 is not a good instrument, since archaeological discoveries might be correlated with modern construction. However, since most Japanese archaeological discoveries of Jomon and Yayoi sites occurred since 1960 [see Koyama (1978)], we used 1920 density data as an instrument for these regressions.

Table 1 reports the Zipf coefficient for each of our time periods. The broad story that it tells confirms the results from the prior non-parametric statistics. Dispersion was relatively high in the Jomon and Yayoi periods - indeed very close to fitting Zipf's Law. Regional variation in density declined modestly for the period 725 to 1600 , before declining sharply in the period in which Japan was closed to the West. Since Japan reopened and began its industrialization, 
regional variation has increased substantially, reaching a Zipf coefficient of -0.96 in 1998. The coefficients are quite precisely estimated. With the exception of the Jomon period, which has a standard error of 0.22 , our standard errors on the Zipf coefficient range from 0.03 in 1998 to 0.17 in the year 900. We cannot statistically distinguish the modern coefficient from that in 1600 or any prior date.

Our examination of 8,000 years of Japanese regional data reveals three important facts. First, regional population densities have always varied greatly in Japan. This is true in the Stone Age, at the dawn of the agricultural revolution, during the long period of feudalism, and it remains true in modern industrial Japan. Indeed, with the exception of Stone Age Japan, our spread of Zipf coefficients is well within the range of coefficients that one would find in a sample of OECD countries [cf. Rosen and Resnick (1980)]. ${ }^{12}$ Second, the closure of Japan to trade for more than two centuries was accompanied by a substantial reduction in the variation of regional population density. Large port-based regions appear to have lost ground relative to regions directed more exclusively to national activity. Third, the industrial revolution in Japan, coming hand in hand with its re-opening to international trade, does seem to have promoted a very high degree of regional concentration and variation in regional population density.

\section{Persistence in Regional Population Densities}

We now turn to consider persistence in the identity of the regions that are densely settled. Table 1 reports both raw and rank correlations between the regional population densities in the

\footnotetext{
${ }^{11}$ On first blush, this might appear to conflict with the results of Eaton and Eckstein (1997) that showed the stability of the Zipf coefficients for Japanese cities over the period 1925-1985. Here the difference between their use of city data and our use of regional data is crucial, since this suggests that even if there is little change in the distribution of city sizes, there may be important spatial correlation among cities that are growing, which could explain the increased variation in regional densities.

${ }^{12}$ Rosen and Resnick (1980) estimate the Zipf relationship for a broad set of countries using a comparable number of observations. Within the OECD countries in their sample, Zipf coefficients range from -0.88 to -1.96 .
} 
various periods with those for 1998. Consider first the Jomon data, dating from Japan's Stone Age (-6,000 to -300). The raw and rank correlations of the density of archaeological sites from this period and 1998 regional population density are 0.53 and 0.31 respectively. The higher raw correlation especially captures the fact that the most densely settled regions are common in the two periods. The lower rank correlation captures the fact that large sections of Japan were relatively untouched by the Jomon people and so the rankings among these are weak.

Consider next the Yayoi period (-300 to 300). Agriculture and metallurgy are just being introduced. Writing has not yet appeared. In the next two millennia, total population will rise by a factor of 200. If we know the distribution of the regional density of archaeological sites from the Yayoi period, how much information would we expect this to provide about the distribution of modern regional population densities? The raw and rank correlations are 0.67 and 0.50 respectively. Given that two millennia of Japanese history separate these dates, with the accompanying economic transformations, we consider this persistence to be quite remarkable.

In moving to the year 725 , we now are able to work with the first census data and ask the same questions. A feudal regime is in place. The vast majority of the population is agricultural. Nonetheless, the raw and rank correlations of regional population densities in 725 and 1998 are 0.60 and 0.71 respectively. Again, these show a remarkable persistence.

We will not discuss every date. Perhaps not surprisingly, there is a general trend that raw and rank correlations with modern regional densities rise pretty steadily. We will cite just one last date. If we look four centuries back to the year 1600, a time in which Japan had a population just over 10 percent of its modern population, the raw and rank correlations with the modern regional densities are 0.76 and 0.83 respectively. 
In sum, it is absolutely striking how much persistence there is in the distribution of regional population density throughout Japanese history. The high correlations trace back virtually to the Stone Age. The correlations between modern regional densities and those of Japan four centuries ago are remarkably strong. Persistence is a very strong feature of the data.

\section{Bombs and Break Points}

Imagine a calamity destroys a large share of a city's productive capacity and drastically reduces its population. Will this temporary shock have permanent effects? Or is there a strong tendency for locations to be robust even to large temporary shocks so that this city will shortly revert to its former place in the constellation of cities? An ideal experiment would have several key features. The shocks would be large, highly variable, clearly identifiable and purely temporary. In this section, we will consider the Allied bombing of Japanese cities during World War II as precisely such an experiment.

\section{A. Data}

Our data covers 303 Japanese cities with population in excess of 30,000 in 1925. Population is recorded at five-year intervals between 1925 and 1965, with the exception that the regular 1945 census is delayed until 1947 due to disruption from the war. These data allow us to compute population growth rates for the pre-war period, 1925-1940; the period of the war itself and its immediate aftermath, 1940-1947; and two measures of the recovery period, 1947-1960 and $1947-1965.13$

One measure of the intensity of the shocks will be the dead and missing city residents due to war actions. The missing are included because the magnitude of the shocks frequently made

\footnotetext{
${ }^{13}$ More detail is provided in the Appendix.
} 
recovery of bodies impossible, as for example with those vaporized by the Hiroshima nuclear blast. In order to have a measure of the intensity of the shocks, the dead and missing will typically enter deflated by the number of city residents in 1940. A second measure of the intensity of the shocks will be the number of buildings destroyed per resident. We also at times report the percentage of the built up area destroyed for the 66 Japanese cities covered by the United States Strategic Bombing Survey.

If we are to understand the impact of private actions that may lead cities to recover, it is important to control for government actions. The Japan Statistical Yearbook provides data on expenditures from US and Japanese government sources designated for the reconstruction of war damage in each prefecture. We allocate these among the cities within the prefecture in proportion to the shares of buildings destroyed in that prefecture. These are divided by the population in the city in 1947 to create our variable, "government reconstruction expenses," which is thousands of yen per capita spent by the government to reconstruct a city. These geographically-directed expenditures are quite small. For example, most food aid, income assistance, and industrial subsidy programs did not discriminate on the basis of location, and therefore do not count as regional subsidies. Interestingly, rural prefectures, which typically sustained less war damage, received significantly more aid relative to the number of buildings destroyed than more urban areas. This was probably due to Japan's long-term policy of subsidizing rural districts at the expense of urban ones.

\section{B. Magnitude of the Shocks}


The Allied strategic bombing in World War II devastated Japanese cities. It targeted sixty-six cities. The bombing destroyed almost half of all structures in these cities - a total of 2.2 million buildings. Two-thirds of productive capacity vanished. Three hundred thousand Japanese were killed. Forty percent of the population was rendered homeless. Some cities lost as much as half of their population owing to deaths, missing, and refugees. 4

The nuclear bombings of Hiroshima and Nagasaki are, of course, well known. The first atomic weapon was dropped on Hiroshima on August 6, 1945, and was the equivalent of 12 kilotons of TNT. The temperature at the blast site is believed to have surpassed one million degrees Celsius. Over two-thirds of the built up area of the city was destroyed. The blast may have killed as many as 80,000 people - more than 20 percent of Hiroshima's population. The second atomic weapon was dropped on Nagasaki on August 9 and had a power nearly twice that of Hiroshima, at 22 kilotons. The hilly topography of Nagasaki and the fact that the bomb missed its target by a wide margin kept the destruction of the built up area under 40 percent. Still, more than 25,000 were killed or went missing, approximately 8.5 percent of city residents.

While the nuclear attacks on Hiroshima and Nagasaki are widely known among the public in the West, the devastation of other Japanese cities is much less well known. An example of the magnitude of the destruction is a single firebombing raid on Tokyo the night of March 9 , 1945. United States B-29 Superfortress bombers, based in the Marianas Islands, flew more than 300-strong over Tokyo that night. Under a new strategy devised by General Curtis LeMay, the bombers flew with minimal defenses and at low altitudes. This allowed them to maximize the payload of napalm incendiaries and to release these at precise intervals. Tokyo had received no rain in a week and the wind that night blew at 25 miles per hour. Tokyo, a city of straw, paper, and wood, lay in wait. The B-29 Superfortresses flew over Tokyo for just three hours on March

\footnotetext{
${ }^{14}$ These numbers are from USSBS (1947).
} 
9, dropping 1.7 kilotons of napalm incendiaries. This unleashed a firestorm. Rivers boiled.

Asphalt streets liquefied and burst into flame. The results were devastating. Sixteen square miles of Tokyo were reduced to ash. At least 80,000 people were killed in that raid alone (Werrell p. 162-3).

The magnitude of destruction in the March 9 raid on Tokyo was large not only by Japanese standards; when it happened, it was the deadliest single-day air attack in the history of the world. The number of people killed was of the same order of magnitude as the nuclear bombing of Hiroshima. Japan suffered more civilian casualties in that one raid than Britain suffered in all of World War II. And this was just the beginning. By the end of the war, the US had destroyed more square miles of Tokyo than the combined destruction in the fifteen most heavily bombed German cities [Werrell (1996) p. 32].

A major reason why Tokyo stands out in Japanese data is due to the fact that with a 1940 population of 7.3 million it was by far the largest target in Japan. Given that Tokyo was sixteen times the size of Hiroshima and more than twenty times the size of Nagasaki, even nuclear bombs could not kill as many people in these smaller cities. This suggests the value of considering destruction in proportional rather than absolute terms. Seen this way, the destruction in the course of the war of 56 square miles of Tokyo only amounted to 50.8 percent of its built up area (USSBS p. 42). This is actually just under the median percentage of urban destruction of 50.9 percent for the 66 targeted cities. In short, in terms of the destruction of built up area for the targeted cities, the devastation of Tokyo we described made it just a typical city. 5

\footnotetext{
${ }^{15}$ The Allies dropped 17 pounds of incendiaries per capita on the median firebombed city, but only 4 pounds per capita on Tokyo. Tokyo nonetheless still stands out for the number who died. It seems likely that in smaller cities there was greater opportunity to escape the firestorms.
} 


\section{Variance of the Shocks}

While the magnitude of the shocks to city sizes was large, there was also a great deal of variability in these shocks. In fact, approximately 80 percent of the 300 cities in our sample, collectively representing 37 percent of the urban population, were virtually untouched by the bombings. This includes large cities. Kyoto, the fifth largest city at the beginning of the war, was not bombed at all. ${ }^{16}$ Given the city’s historical significance, it was believed that its destruction might strengthen the Japanese will to resist. The large cities of Niigata and Kitakyushu escaped substantial damage because they were preserved as potential nuclear bomb targets. Cities in the North of Japan, such as Sapporo, escaped heavy bombing because they were largely out of range of US bomber forces.

Even among those cities that did suffer firebombing, there is a high degree of variability in the destruction. One reason is learning by doing. The creation of a firestorm from napalm incendiaries depended on having a sufficient number of planes, dropping the incendiaries in precise patterns and at relatively close intervals. While some tests of the incendiaries had been conducted on mock Japanese cities at the Dugway Proving Grounds in Utah, it was only as a result of the experience of actual bombing raids that US forces achieved the optimal pattern. Moreover, cities such as Nagoya, which were firebombed early, had as a result of those raids the equivalent of firebreaks within the city. In the subsequent raids, it became nearly impossible to create highly destructive firestorms.

In addition, there were a large number of other factors at work that created variance in the destruction of cities. These include the steady growth in the number of B-29s available for service; the evolving defense capabilities of the Japanese cities (which was important notably for

\footnotetext{
${ }^{16}$ Our definition of "virtually untouched" is casualties of under 100. Hammel (1998) reports no air attacks on Kyoto. Nakamura and Miyazaki (1995) do report 82 casualties in Kyoto (1940 Pop. 1.1 million) due to the war. Presumably these were due to targeting errors, strafing, and/or Kyoto residents who were killed in other cities.
} 
Osaka); the topography of specific cities; and sheer fortune, as in the fact that Nagasaki was bombed only when the primary target, Kokura (now Kitakyushu), could not be visually identified due to cloud cover.

\section{Temporary Nature of the Shocks}

Rarely does one find shocks that can so clearly be identified as temporary. For much of World War II, Japanese cities were simply out of range of US bombers. In the first year of the war, the US managed only the single "Doolittle raid" on Japan from a US carrier, and this had little more than psychological impact. Later, the US tried to use China as a base for attacks on Japanese cities. But the long flights required and the difficult supply lines insured that these had only minimal effect. It was only with the capture of the Marianas islands as a B-29 base, the seizure of Iwo Jima (which lay directly between the Marianas and Japan) as a base for fighter escorts, a rise in the number of planes available, and the introduction of new tactics by General LeMay that the US attacks reached an apogee. The most powerful attacks were compressed in the last five months of the war.

While the devastation of many of these cities was powerful, once the flames were out, the geographical characteristics of particular locations are affected little or not at all. The one possible exception, of course, is the lingering radiation in Hiroshima and Nagasaki. This will make these particularly interesting cases to see whether they were special cases in the period of recovery from the war.

\section{E. Impact of the Shocks: Temporary or Permanent?}


We now inquire whether temporary shocks have permanent effects on relative city sizes. Let $S_{i t}$ be city $i$ 's share of total population at time $t$, and let $s_{i t}$ be the natural logarithm of this share. Suppose further that each city has an initial size $\Omega_{i}$ and is buffeted by city-specific shocks $\varepsilon_{i t}$. In this case we can write the size of any city at any point in time as,

$$
s_{i t}=\Omega_{i}+\varepsilon_{i t}
$$

We can model the persistence in these shocks to population shares as:

$$
\varepsilon_{i t+1}=\rho \varepsilon_{i t}+v_{i t+1}
$$

The parameter $\rho \in[0,1]$ and the innovation, $v_{i t}$, is an iid error term.

We examine the evolution of this system by first differencing equation 11 . This yields

$$
s_{i t+1}-s_{i t}=\varepsilon_{i t+1}-\varepsilon_{i t}
$$

If we substitute equation (2) into equation (3), we then obtain

$$
s_{i t+1}-s_{i t}=(\rho-1) v_{i t}+\left[v_{i t+1}+\rho(1-\rho) \varepsilon_{i t-1}\right]
$$

The key parameter is $\rho$, which tells us how much of a temporary shock is dissipated in one period. If $\rho=1$, then all shocks are permanent and city size follows a random walk. In this case,

$$
s_{i t+1}=s_{i t}+v_{i t+1}
$$

If $\rho \in[0,1)$, then city share is stationary and any shock will dissipate over time. In other words, these two hypotheses can be distinguished by identifying the parameter $\rho$.

One approach to investigating the magnitude of $\rho$ is to search for a unit root. It is well known that unit root tests usually have little power to separate $\rho<1$ from $\rho=1$. This is due to the fact that in traditional unit root tests the innovations are not observable and so identify $\rho$ with

\footnotetext{
${ }^{17}$ Equation (5) is identical with the key equation in Gabaix (1999).
} 
very large standard errors. A major advantage of our data set is that we can easily identify the innovations due to bombing. In particular, since by hypothesis the innovation, $v_{i t}$, is uncorrelated with the term in square brackets, then if we can identify the innovation, we can obtain an unbiased estimate of $\rho$.

An obvious method of looking at the innovation is to use the growth rate from 1940 to 1947. However, this measure of the innovation may contain not only information about the bombing but also past growth rates. This is a measurement error problem that could bias our estimates in either direction depending on $\rho$. In order to solve this, we instrument the growth rate from 1940-47 with buildings destroyed per capita and deaths per capita.

We can obtain a general feel for the data by considering the impact of bombing on city growth rates. As we argued earlier, if city growth rates follow a random walk, then all shocks to cities should be permanent. In this case, one should expect to see no relationship between historical shocks and future growth rates. Moreover, if one believes that there is positive serial correlation in the data, then one should expect to see a positive correlation between past and future growth rates. By contrast, if one believes that location specific factors are crucial in understanding the distribution of population, then one should expect to see a negative relationship between a historical shock and the subsequent growth rate. In Figure 1 we present a plot of population growth between 1947 and 1960 with that between 1940 and 1947. The sizes of the circles represent the population of the city in 1925. The figure reveals a very clear negative relationship the two growth rates. This indicates that cities that suffered the largest

\footnotetext{
${ }^{18}$ The actual estimating equation is $s_{i 60}-s_{i 47}=(\rho-1) v_{l 47}+\left[v_{i 60}+\rho(\rho-1) \varepsilon_{i 34}\right]$. Our measure of the shock is the growth rate between 1940 and 1947 or $s_{i 47}-s_{i 40}=v_{i 47}+\left[\rho \varepsilon_{i 34}-\varepsilon_{i 40}\right]$. This is clearly correlated with error term in the estimating equation, hence we instrument.
} 
population declines due to bombing tended to have the fastest postwar growth rates, while cities whose populations boomed conversely had much lower growth rates thereafter.

In Table 2, we present a regression showing the power of our instruments. Deaths per capita and destruction per capita explain about 41 percent of the variance in population growth of cities between 1940 and 1947. Interestingly although both have the expected signs, destruction seems to have had a more pronounced effect on the populations of cities. Presumably, this is because, with a few notable exceptions, the number of people killed was only a few percent of the city's population.

We now turn to test whether the temporary shocks give rise to permanent effects. In order to estimate equation (4), we regress the growth rate of cities between 1947 and 1960 on the growth rate between 1940 and 1947 using deaths and destruction per capita as instruments for the wartime growth rates. The coefficient on growth between 1940 and 1947 corresponds to ( $\rho$ 1). In addition, we include government subsidies to cities to control for policies designed to rebuild cities.

If one believes that cities follow a random walk or that catastrophes can permanently alter the size of cities, then one should expect the coefficient on the 40-47 growth rate, $(\rho-1)$, should be zero. If one believes that the temporary shocks have only temporary effects, then the coefficient on 40-47 growth should be negative. A coefficient of minus one indicates that all of the shock was dissipated by 1960 .

The results are presented in Table 3. The coefficient on 40-47 growth is -1.0 , indicating that at this interval $\rho$ is zero. This means that the typical city completely recovered its former relative size within 15 years following the end of World War II. Given the magnitude of the destruction, this is quite surprising. Apparently, US bombing of Japanese cities had no impact on 
the typical city's size in 1960. This strongly rejects the hypothesis that growth in city size share is a random walk.

As expected, reconstruction subsidies seem to have had a positive and statistically significant impact on rebuilding cities. However, the economic impact is quite modest. Our estimates suggest that a one standard deviation increase in reconstruction expenses would increase the size of a city in 1960 by 2.2 percent. Reconstruction expenses probably had a small effect because both the sums spent and the variance in the sums were small. In the cities that suffered the heaviest destruction - Tokyo, Hiroshima, Nagasaki, and Osaka - our estimates indicate that government reconstruction expenses accounted for less than one percentage point of their cumulative growth between 1947 and 1960. Given that cumulative growth in these cities over that period was between 55 and 96 percent, we conclude that reconstruction expenses had relatively small impacts. As we noted earlier, a major reason for this was that reconstruction policies, like most Japanese regional policies, disproportionately sent money to rural areas. As a result, the four biggest per capita recipients of assistance were small northern cities that were never targeted by US bombers.

One potential problem with these results is that it is possible that the US inadvertently targeted cities based on underlying growth rates. While this was not an explicit strategy, we cannot rule it out. If the US bombed rapidly growing cities more heavily, then we may be biasing our results downwards. We therefore repeated our exercise adding the growth rate between 1925 and 1940 to our list of independent variables. This improves the fit, but does not qualitatively change the results, although the coefficient on $40-47$ growth falls to -0.76 . This implies that bombed cities had recovered over three-fourths of their lost growth by 1960 . One reasonable question to ask, then, is whether these cities ever returned to their prewar trajectories 
or not. If one believes in the location specific model, then one should expect that the coefficient on wartime growth should asymptotically approach unity as the end period increases. In the last column of Table 3 we repeat the regression, only now extending the endpoint to 1965 instead of 1960. The estimated coefficient now reaches -1.0 . That is, after controlling for prewar growth trends, by 1965 cities have entirely reversed the damage due to the war. Again, the impact of reconstruction subsidies also lessens as we move into the future. Together, these results suggest that the effect of the temporary shocks vanishes completely in less than twenty years.

One possible objection to our interpretation is that in most cases, the population changes corresponded much more to refugees than deaths. Of the 144 cities with positive casualties, the average number of deaths per capita was only 1 percent. Most of the population movement that we observe in our data is due to the fact that the vast destruction of buildings forced people to live elsewhere. However, forcing them to move out of their cities for a number of years may not have sufficed to overcome the social networks and other draws of their home cities. Hence it may seem uncertain whether they are moving back to take advantage of particular characteristics of these locations or simply moving back to the only real home they have known.

However, there are two cases in which this argument cannot be made: Hiroshima and Nagasaki. In those cities, the number of deaths was such that if these cities recovered their populations, it could not be because residents who temporarily moved out of the city returned in subsequent years. We have already noted that our data underestimates casualties in these cities. Even so, our data suggest that the nuclear bombs immediately killed 8.5 percent of Nagasaki's population and 20.8 percent of Hiroshima's population. Moreover given that many Japanese were worried about radiation poisoning and actively discriminated against atomic bomb victims, it is unlikely that residents felt an unusually strong attachment to these cities or that other 
Japanese felt a strong desire to move there. Another reason why these cities are interesting to consider is that they were not particularly large or famous cities in Japan. Their 1940 populations made them the $8^{\text {th }}$ and $12^{\text {th }}$ largest cities in Japan. Both cities were close to other cities of comparable size so that it would have been relatively easy for other cities to absorb the populations of these devastated cities.

In Figure 2 we plot the population of these two cities. What is striking in the graph is that even in these two cities there is a clear indication that they returned to their prewar growth trends. This process seems to have taken a little longer in Hiroshima than in other cities, but this is not surprising given the level of destruction.

Taken together, these tests establish that even the spectacular destruction inflicted on Japanese cities by the US Strategic Bombing of Japanese cities in WWII had virtually no long run impact on the relative size of Japanese cities. Within the space of just twenty years, they recovered from the devastation to return to their former place in the constellation of cities.

\section{Three Theories in Light of the Evidence}

The preceding two sections establish a series of stylized facts about the economic geography of Japan. It is now time to collect those facts and consider them in light of the major theories. The facts are: (1) A high degree of variation in Japanese regional density has existed at all points in time. (2) Zipf's law holds approximately for the distribution of regional densities throughout Japanese history. (3) The variation in regional densities begins to rise in the very period that Japan re-opens to the world economy and begins its industrialization. (4) There is tremendous persistence in the identity of the most densely settled regions. (5) Even very strong temporary shocks have virtually no permanent impact on the relative size of cities. 
The three theories that we have identified are increasing returns (IR), random growth (RG), and locational fundamentals (LF). Properly, the IR approach is less a theory than a family of theories with common structural elements. Hence we do not think it is appropriate to consider our exercises a test of the IR theories. Rather, we will use the facts to consider which of various themes that have featured prominently within the IR literature. We summarize our findings in Table 4 where a "+" indicates that the stylized fact is predicted by the theory, a "-" indicates that the theory does not predict it, and a question mark indicates that the theory either makes no prediction or is ambiguous.

As a point of analysis, the increasing returns theories frequently ask how spatial differentiation may emerge even in a framework in which all locations are identical in terms of economic primitives (FKV 1999). From an analytic standpoint, this is precisely the right starting point because it emphasizes theoretical features of the IR approach that are unique and surprising. However, it is an empirical question how much of the actual variation in regional densities owes to IR forces and how much to other factors. An extremely important advantage of the long time series with which we work is that it is both able to examine the distribution of regional densities for a period in which the forces of increasing returns must have been vastly weaker than they are today and also to see if there is a rise in regional variation in the period in which the theory predicts there should be.

The fact that there has been a high degree of variation in regional population densities at all points in Japanese history, even those in which increasing returns is most likely of at most modest importance, strongly suggest that there are forces quite apart from increasing returns that have long been important contributors to this regional variation. However, the fact that the variation in regional population density rose precisely in the period in which Japan industrialized 
is something that we may well have expected based on the IR approach. This seems reasonably strong evidence that IR theories do have something important to contribute to a complete theory of economic geography.

We have noted that the Zipf relation holds reasonably well for the distribution of regional densities, just as it does for the distribution of city sizes. Fujita, Krugman, and Venables (1999) have been very forthright that the IR theories provide no obvious account for the Zipf relation.

The IR theories do not provide a definitive answer to the degree of persistence one should expect in regional densities. One strand of the theory, due to Henderson (1974), ties city sizes to technological characteristics of specific industries. Since we are looking over periods with very radical shifts in industrial structure, one might on this basis suppose that there would be similarly radical shifts in regional densities (which we don't observe). However, there is an alternative tradition within the IR approach, typified by Paul David (2000) and very evident in FKV (1999), which stresses the role of path dependence. Small initial advantages cumulate, so that even as the industrial structure changes radically, the head start provides an advantage in the next stage of locational competition. It seems to us that if one is to interpret the strong locational persistence from the perspective of the IR framework that one does need to rely strongly on path dependence.

Finally, again the IR framework does not provide a unique answer to whether temporary shocks will have permanent effects. Nonetheless, the investigation of the bombing of Japanese cities does prove useful. One of the most striking features of the IR literature is the existence of bifurcations in parameter space - what FKV term break points and sustain points - which 
separate radically different spatial equilibria. ${ }^{19}$ The literature emphasizes as well that because of the existence of multiple stable equilibria, there may be irreversibility of these changes even when the forces that brought about the initial change are reversed. An important practical question, then, is whether such spatial catastrophes are theoretical curiosa or a central tendency in the data. Our results provide an unambiguous answer: Even nuclear bombs have little effect on relative city sizes over the course of a couple of decades. The theoretical possibility of spatial catastrophes due to temporary shocks is not a central tendency borne out in the data.

The random growth (RG) theory can be discussed briefly. The most important advantage of the RG theory over the IR theory is simply that it provides a foundation for understanding the Zipf distribution, which is also evident in the distribution of regional densities. The existence of substantial variation in regional densities across all of Japanese history is consistent with the RG theory provided the stochastic process starts sufficiently far back in time. The persistence of the identity of the densely settled regions can be made consistent with the RG theory only if one is willing to believe that the variance of growth rates is quite small. The RG theory provides no explanation why the industrial revolution in Japan should have been accompanied by a rise in the variation in regional densities. However, the most devastating strike against the RG theory comes from the examination of the bombing data. The RG theory holds that growth will be a random walk. This is strongly rejected by the data on the recovery of Japanese cities in the wake of the WWII bombing. Hence we consider this a decisive rejection of the pure RG theory.

The locational fundamentals (LF) theory holds that there are permanent features of specific locations that make these locations an excellent site for economic activity. Access to the sea, rivers, and a large plain has been useful at all points in time. Location on a mountaintop, in

\footnotetext{
${ }^{19}$ Formally, a break point is a parameter value that marks a threshold between values for which a symmetric equilibrium is stable or not. A sustain point, similarly, is the threshold governing the stability of a concentrated equilibrium.
} 
the desert, or in harsh climactic conditions has always been a disadvantage. This provides a very natural account of the high degree of variation in regional densities at all points in time. If these fundamentals are distributed as suggested by Krugman (1996) and Gabaix (1999), then they also provide an account for Zipf's law. Persistence is highly compatible with this account. Moreover, since the bombing of cities would not be expected to affect these fundamentals, the LF theory provides a very natural account for the postwar mean reversion of cities. The one area in which there seems to be an important shortfall is that the LF theory does not provide an obvious explanation for the rise in the variation of regional densities coincident with the industrial revolution in Japan.

\section{Policy}

While we do not directly examine any policy interventions, our results are pertinent to policy discussions. One of the most important reasons for the renewed interest in economic geography is precisely the possibility that in a world of cumulative causation, path dependence, and critical break points, even temporary policy interventions may alter the long run spatial structure of economic activity. These in turn may have important welfare consequences, particularly for immobile factors in the regions favored or not. Our results suggest a great deal more stability in the spatial structure of economies than one might have guessed. There is tremendous persistence in which regions are most densely settled, even as the economy passes through multiple economic revolutions - the rise of agriculture, the rise and decline of feudalism, the move to autarky and the reversal to free trade, and finally the rise of the industrial revolution. Destruction of half or more of a city's structures and killing as much as 20 percent of its population does little to disturb the long run relative size of a city. In the face of these facts, how 
much chance is there that temporary subsidies of economically relevant magnitudes will significantly alter the long run spatial structure of an economy?

Jeffrey Sachs and various co-authors have raised a policy-relevant question bearing on issues of economic development. 2 To what extent is geography destiny? Is living in the tropics instead of a temperate zone a long run impediment to economic development? Is the lack of a coast or navigable rivers an insuperable obstacle to growth? We believe that the evidence we provide complements the results of Sachs and others which stress that there are deep, very likely geographical, characteristics of particular locations that have a very strong influence on their opportunities for growth relative to other locations in a common technological regime.

\section{Conclusions}

We began with the defining question of economic geography: What gives rise to the observed variation in economic activity across regions? It is impossible, of course, to provide final answers to such an important question on the basis of one study of the experience of one country. Nonetheless, we believe that the present study does allow important progress in understanding this question.

We examined data on regional population density in Japan from the Stone Age to the modern era. We also considered the implications for relative city sizes of the Allied bombing of Japanese cities during World War II. These data exercises allowed us to develop a number of key stylized facts. Variation in regional population density has been high at all points in time, obeys Zipf's law, and rose in the period coincident with the industrial revolution. There is a great deal

\footnotetext{
${ }^{20}$ It is important to note that for these issues, the degree of geographical aggregation may matter. For example, it may well be that Tokyo was destined to be a great city, but it may have been harder to say which sub-regions of Tokyo would take on the specific character that they have. Similarly, this need not rule out that such subsidies could importantly affect the industrial mix as opposed to aggregate activity.

${ }^{21}$ Cf. Rappaport and Sachs (2001), Gallup, Sachs, and Mellinger (1999), etc.
} 
of persistence in the identity of the most densely settled regions. And temporary shocks, even of frightening magnitude, appear to have little long run impact on the spatial structure of the economy.

We then used these facts to consider three prominent theories designed to explain the distribution of city sizes. The simple random growth theory of Simon (1955) and Gabaix (1999) is decisively rejected by the bombing experiment, since that theory counterfactually predicts that city sizes will follow a random walk. The strongest point in favor of the increasing returns theory is its clear suggestion that industrialization should have raised the variation of regional densities, a prediction confirmed by the data. The locational fundamentals theory emerges as an important part of a full account. It can explain why there is a great deal of variation in regional densities long before increasing returns is a plausible account; it explains why the densities obey Zipf's law - something the increasing returns theory cannot do; it predicts a great deal of persistence in the distribution of regional densities; and it predicts that even quite large temporary shocks will have little long run impact. The one dimension in which the increasing returns theory clearly dominates the locational fundamentals theory is the account that it provides of the rise in the variation of regional densities in the period of industrialization. Taken together, these considerations lead us to favor a hybrid theory in which locational fundamentals play a leading role in accounting for the spatial pattern of relative regional densities, but increasing returns may help to determine the degree of spatial differentiation. 
Table 1

\begin{tabular}{|c|c|c|c|c|c|c|c|}
\hline Year & $\begin{array}{l}\text { Population } \\
\text { in } \\
\text { Thousands }\end{array}$ & $\begin{array}{l}\text { Share of } 5 \\
\text { Largest } \\
\text { Regions }\end{array}$ & $\begin{array}{l}\text { Relative } \\
\text { Var of log } \\
\text { Pop Den }\end{array}$ & $\begin{array}{l}\text { Zipf } \\
\text { Coefficient }\end{array}$ & $\begin{array}{l}\text { Raw } \\
\text { Correlation } \\
\text { with } 1998 \\
\end{array}$ & $\begin{array}{l}\text { Rank } \\
\text { Correlation } \\
\text { with } 1998\end{array}$ & History \\
\hline $\begin{array}{r}-6000 \text { to } \\
-300\end{array}$ & 125 & 0.39 & 2.46 & $\begin{array}{l}-0.809 \\
(0.217)\end{array}$ & 0.53 & 0.31 & $\begin{array}{l}\text { Hunter-gatherer society, not ethnically Japanese, no metal tools or } \\
\text { agriculture. }\end{array}$ \\
\hline $\begin{array}{r}-300 \text { to } \\
300\end{array}$ & 595 & 0.23 & 0.93 & $\begin{array}{l}-1.028 \\
(0.134)\end{array}$ & 0.67 & 0.50 & $\begin{array}{l}\text { First appearance of primitive agriculture and ethnically Japanese } \\
\text { people. Some metallurgical skills, some coins, no writing or cloth. }\end{array}$ \\
\hline 725 & 4511 & 0.20 & 0.72 & $\begin{array}{l}-1.207 \\
(0.133)\end{array}$ & 0.60 & 0.71 & $\begin{array}{l}\text { Creation of feudal regime, population censuses begin, writing well } \\
\text { developed, farming is widespread. Capital is Nara. }\end{array}$ \\
\hline 800 & 5506 & 0.18 & 0.75 & $\begin{array}{l}-1.184 \\
(0.152)\end{array}$ & 0.57 & 0.68 & $\begin{array}{l}\text { Capital Moves to Kyoto. Property rights for peasant farmers } \\
\text { continue to improve leading to greater cultivation. }\end{array}$ \\
\hline 900 & 7442 & 0.29 & 0.68 & $\begin{array}{l}-1.230 \\
(0.166)\end{array}$ & 0.48 & 0.65 & $\begin{array}{l}\text { Use of metallic farm tools doubles over average for previous } 300 \\
\text { years. Improved irrigation and dry-crop technology. }\end{array}$ \\
\hline 1150 & 6836 & 0.20 & 0.66 & $\begin{array}{l}-1.169 \\
(0.141)\end{array}$ & 0.53 & 0.73 & $\begin{array}{l}\text { Multiple civil wars especially in (rice-rich) northern Japan. } \\
\text { General political instability and rebellions. }\end{array}$ \\
\hline 1600 & 12266 & 0.30 & 0.64 & $\begin{array}{l}-1.192 \\
(0.068)\end{array}$ & 0.76 & 0.83 & $\begin{array}{l}\text { Reunification achieved after bloody war, extensive contact with } \\
\text { West. Japan is a major regional trading and military power. }\end{array}$ \\
\hline 1721 & 31290 & 0.21 & 0.43 & $\begin{array}{l}-1.582 \\
(0.113)\end{array}$ & 0.85 & 0.84 & $\begin{array}{l}\text { Closure of Japan to trade with minor exceptions around Nagasaki. } \\
\text { Capital moves to Tokyo. Political stability achieved. }\end{array}$ \\
\hline 1798 & 30531 & 0.21 & 0.37 & $\begin{array}{l}-1.697 \\
(0.120)\end{array}$ & 0.83 & 0.81 & $\begin{array}{l}\text { Population is approximately } 80 \% \text { farmers, } 6 \% \text { nobility. Population } \\
\text { stability attributed to infanticide, birth control, and famines. }\end{array}$ \\
\hline 1872 & 33748 & 0.18 & 0.30 & $\begin{array}{l}-1.877 \\
(0.140)\end{array}$ & 0.76 & 0.78 & $\begin{array}{l}\text { Collapse of shogun's government, civil war, jump to free trade, end } \\
\text { of feudal regime, start subsidized import of foreign technology }\end{array}$ \\
\hline 1920 & 53032 & 0.25 & 0.43 & $\begin{array}{l}-1.476 \\
(0.043)\end{array}$ & 0.94 & 0.93 & $\begin{array}{l}\text { Industrialization and militarization in full swing, but still } 50 \% \text { of } \\
\text { labor force is farmers. Japan is a major exporter of silk and } \\
\text { textiles. }\end{array}$ \\
\hline 1998 & 119486 & 0.41 & 1.00 & $\begin{array}{l}-0.963 \\
(0.025)\end{array}$ & 1.00 & 1.00 & $\begin{array}{l}\text { Japan is a fully industrialized country, Tokyo, with a population of } \\
12 \text { million, is one of the largest cities in the world. }\end{array}$ \\
\hline
\end{tabular}




\section{Table 2}

Instrumental Variables Equation

Dependent Variable is the rate of growth in city population between 1940 and 1947

\begin{tabular}{lc}
\hline Constant & $\begin{array}{c}0.213 \\
(0.006)\end{array}$ \\
& \\
Deaths Per Capita & -0.665 \\
& $(0.506)$ \\
& \\
Buildings Destroyed & -2.335 \\
Per Capita & $(0.184)$ \\
$R^{2}$ & 0.409 \\
Number of & 303 \\
Observations & \\
\hline
\end{tabular}

Standard errors in parentheses 


\section{Table 3}

Two-Stage Least Squares Estimates of Impact of Bombing on Cities (Instruments: deaths per capita and buildings destroyed per capita)

\begin{tabular}{lccc}
\hline & $\begin{array}{c}\text { Dependent variable is } \\
\text { growth rate of population } \\
\text { between 1947 and 1960 }\end{array}$ & $\begin{array}{c}\text { Dependent variable } \\
\text { is growth rate of } \\
\text { population between } \\
1947 \text { and } 1965\end{array}$ \\
\hline $\begin{array}{l}\text { Growth Rate of population } \\
\text { between 1940 and 1947 }\end{array}$ & -1.048 & -0.759 & -1.027 \\
Government reconstruction & $(0.097)$ & $(0.094)$ & $(0.163)$ \\
expenses & 1.024 & 0.628 & 0.392 \\
$\begin{array}{l}\text { Growth Rate of population } \\
\text { between 1925 and 1940 }\end{array}$ & $(0.387)$ & $(0.298)$ & $(0.514)$ \\
$R^{2}$ & & 0.444 & 0.617 \\
Number of Observations & & $(0.054)$ & $(0.092)$ \\
\hline
\end{tabular}

Standard errors in parentheses 


\section{Table 4}

Match Between Theories and Predictions

\begin{tabular}{|l|c|c|c|}
\hline Stylized Fact & Increasing Returns & Random Growth & Locational Fundamentals \\
\hline $\begin{array}{l}\text { Large Variation in } \\
\text { Regional Densities } \\
\text { at all Times }\end{array}$ & - & + & $\mathbf{+}$ \\
\hline Zipf's Law & - & $\mathbf{+}$ & $\mathbf{+}$ \\
\hline $\begin{array}{l}\text { Rise in Variation } \\
\text { with Industrial } \\
\text { Revolution }\end{array}$ & + & $\mathbf{?}$ & $\mathbf{-}$ \\
\hline $\begin{array}{l}\text { Persistence in } \\
\text { Regional Densities }\end{array}$ & $\mathbf{?}$ & $\mathbf{+}$ \\
\hline $\begin{array}{l}\text { Mean Reversion } \\
\text { After Temporary } \\
\text { Shocks }\end{array}$ & $\mathbf{?}$ & $\mathbf{+}$ & $\mathbf{+}$ \\
\hline
\end{tabular}


Figure 1

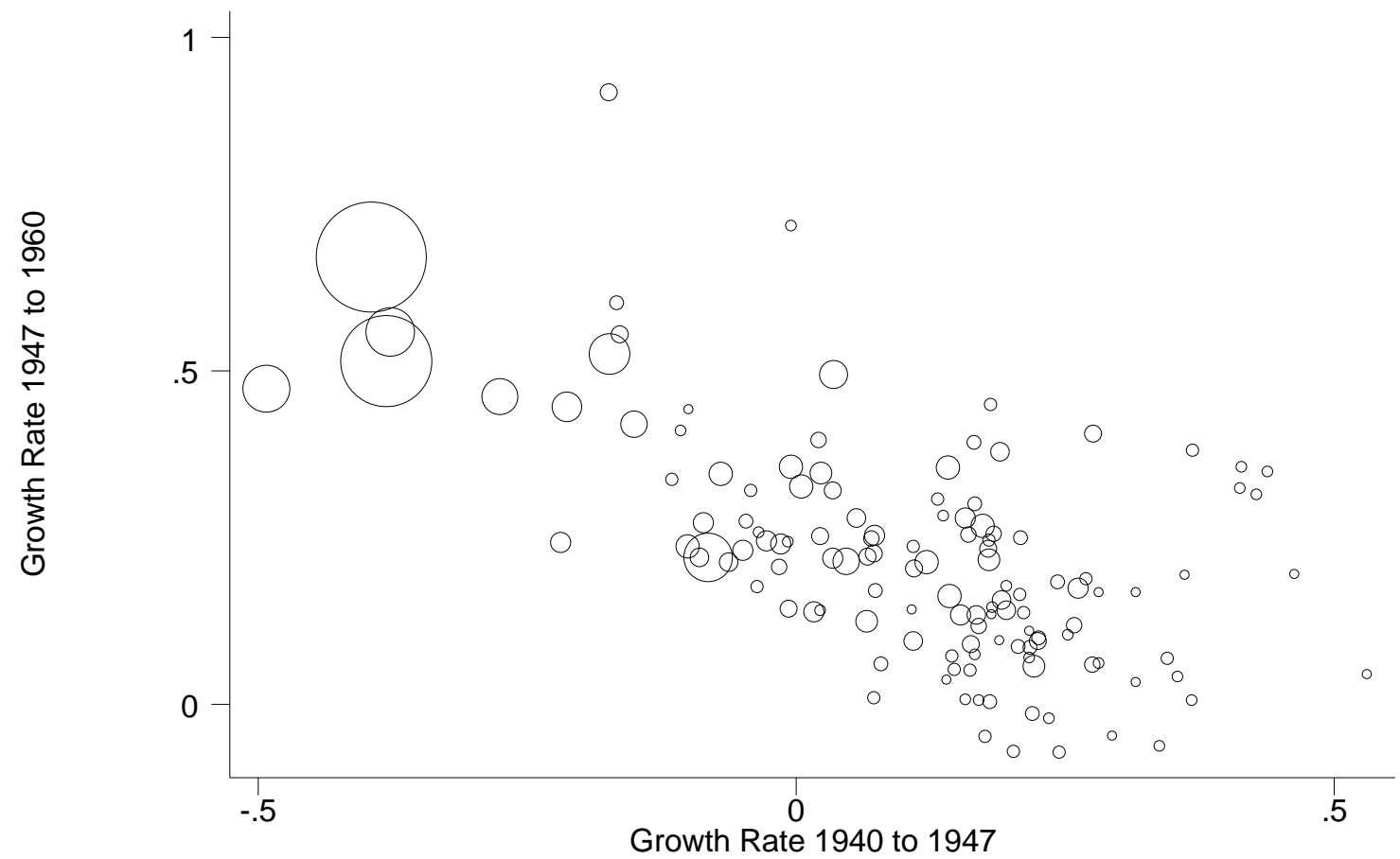

Effects of Bombing on Cities with More than 30000 Inhabitants

(Cities with Positive Casualty Rates Only) 


\section{Figure 2}

\section{Population Growth}

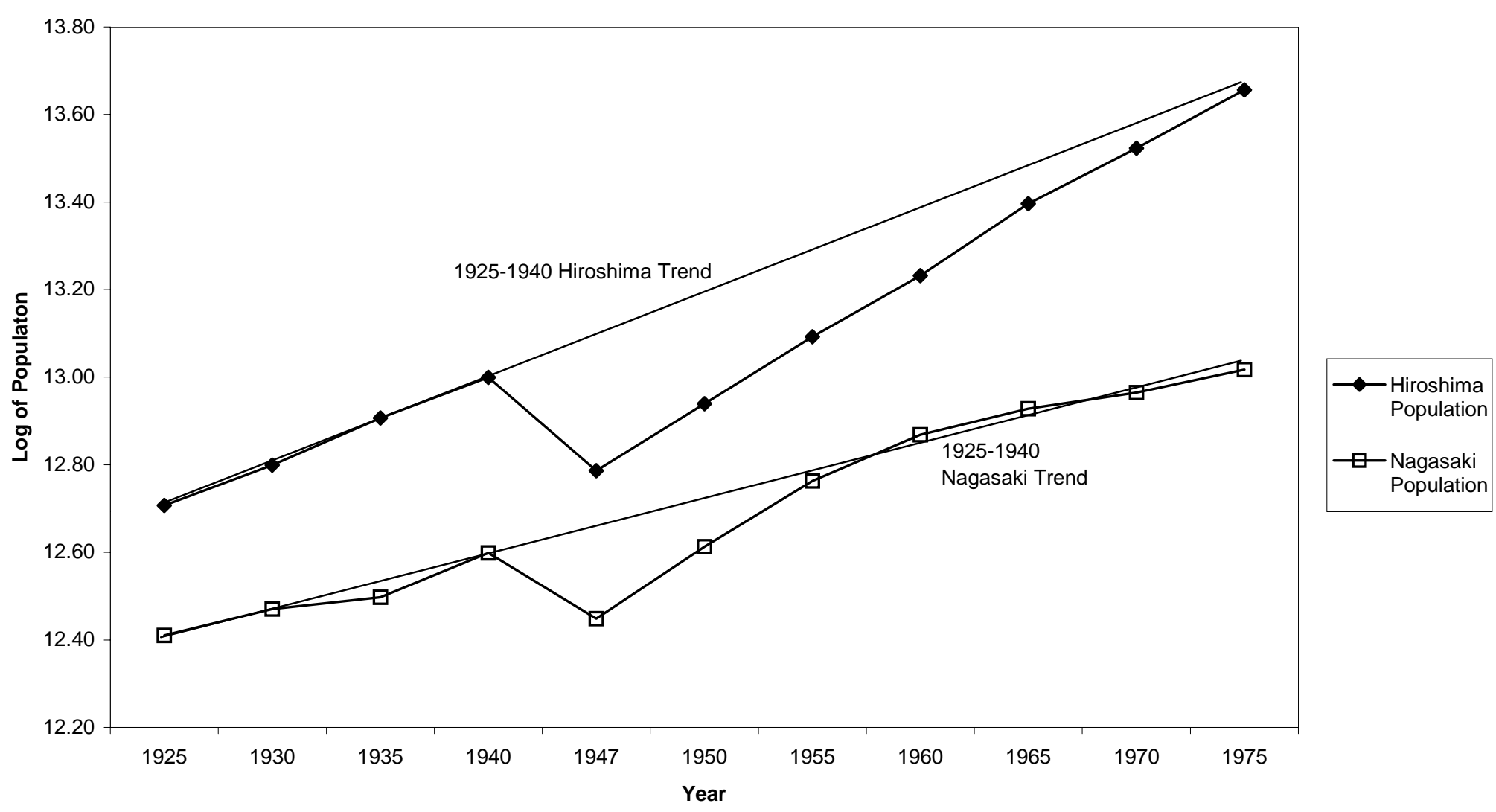




\section{References}

David, Paul A. (2000) 'Path Dependence, Its Critics, and the Quest for 'Historical Economics,' Stanford University Working Papers 00-011.

Eaton, Jonathan; Eckstein, Zvi (1997) "Cities and Growth: Theory and Evidence from France and Japan," Regional Science and Urban Economics, vol. 27, no. 4-5, August, pp. 44374.

Farris, W. Wayne (1984) Population, Disease, and Land in Early Japan: 645-900, Cambridge: Harvard University Press.

Fujita, M., P. R. Krugman, and A. J. Venables (1999) The Spatial Economy: Cities, Regions, and International Trade, Cambridge: The MIT Press.

Fujita M., Mori T. (1996) "The role of ports in the making of major cities: Self-agglomeration and hub-effect," Journal of Development Economics, 49 (1): 93-120 APR.

Fujita M, Thisse JF (1996) "Economics of agglomeration," Journal of the Japanese and International Economies, 10 (4): 339-378 DEC.

Gabaix, Xavier (1999) “Zipf's Law for Cities: An Explanation” Quarterly Journal of Economics, 114 (3), August 1999, pages 739-67.

Gallup, John, Jeffrey Sachs, and Andrew Mellinger (1999) "Geography and Economic Development," International Regional Science Review, vol. 22, no. 2, August, pp. 179232

Hall, James Whitney (1979) Japan: From Prehistory to Modern Times, New York: Dell Publishing Co., Inc.

Hall, James Whitney (1968) “The Castle Town and Japan's Modern Urbanization,” in Hall, James Whitney and Marius B. Jansen eds. Studies in the Institutional History of Early Modern Japan, Princeton University Press, pp. 169-188.

Hammel, Eric (1998) Air War Pacific: America's Air War Against Japan in East Asia and the Pacific 1941-1945 Chronology, Pacifica: Pacifica Press.

Hanley, Susan B. and Kozo Yamamura (1977), Economic and Demographic Change in Preindustrial Japan, 1600-1868.

Henderson, J.V. (1974) “The Sizes and Types of Cities," American Economic Review 64: 64056.

Kito, Hiroshi (1996) "[Chosa] Meiji Izen Nihon no Chiiki Jinko" [The Regional Population of Japan before the Meiji Period], Jochi Keizai Ronsyu, Vol. 41, No.1-2. 
Koyama, Shuzo, “Jomon Subsistence and Population,” Senri Ethnological Studies, 2, 1978.

Krugman, P. R. (1991a) “Increasing Returns and Economic Geography,” Journal of Political Economy, 99: 483-499.

Krugman, Paul R. (1991b) "History versus Expectations," Quarterly Journal of Economics, vol. 106, no. 2, May, pp. 651-67.

Krugman, Paul R. (1995) “Incidents from My Career,” www.pkarchive.org.

Krugman, P. R. (1996) "Confronting the Mystery of Urban Hierarchy," Journal of the Japanese and International Economies, vol. 10, no. 4, December 1996, pp. 399-418.

Krugman, Paul R. (1998) "What's New about the New Economic Geography?" Oxford Review of Economic Policy, vol. 14, no. 2, Summer 1998, pp. 7-17.

Lucas, Robert E , Jr. (2001) "Externalities and Cities," Review of Economic Dynamics, vol. 4, no. 2, April 2001, pp. 245-74.

Management and Coordination Agency of Japan, Nihon Choki Tokei Soran (Historical Statistics of Japan), Vol.1, 1987, pp.94-104.

Naikaku tokei-kyoku (1882) Dai-Nihon Teikoku Tokei Nenkan [Japanese Imperial Statistical Yearbook], Tokyo: Tokyo Tokei Kyokai.

Nakamura, Takahide, and Masayasu Miyazaki. ed., Shiryo Taiheiyo Senso Higai Chosa Hokoku [Damage Survey Report of the Second World War] Todai Shuppankai, 1995.

Neary JP, (2001) “The spatial economy: Cities, regions and international trade by Fujita M, Krugman P, Venables AJ,” Journal of Economic Literature, 39 (2): 536-561 June.

Rosen, Kenneth T.; Resnick, Mitchel (1980) "The Size Distribution of Cities: An Examination of the Pareto Law and Primacy" Journal of Urban Economics;8(2), September, pages 16586.

Rappaport, Jordan and Jeffrey D. Sachs (2001) “The US as a Coastal Nation,” Mimeo.

Sachs, Jeffrey D. (2001) “Tropical Underdevelopment,” NBER Working Paper 8119, February.

Sawada, Goichi (1927) Nara-cho jidai minsei keizai no suteki kenkyu [Numerical Analysis of the Nara Period Economy], Tokyo : Fuzanbo.

Sekiyama, Naotaro (1958) Kinsei Nihon No Jinko Kozo: Tokugawa Jidai No Jinko Chosa To Jinko Jotai Ni Kansuru Kenkyu, [Modern Japanese Population Structure: Research on Tokugawa Population Censuses and Situation] Tokyo: Yoshikawa Kobunkan. 
Statistics Bureau of the Prime Minister's Office, Nihon Tokei Nenkan (Japan Statistical Yearbook), 1950, pp.154-155.

Simon, H. (1955) “On a class of skew distribution functions," Biometrika 42: 425-440.

Toyo Keizai Shinposha. ed. Kanketsu Showa Kokusei Soran [Complete Showa Census Compendium] Vol.1, 1991.

United States Strategic Bombing Survey (1947) Effects of Air Attack on Japanese Urban EconomyVol. 55, Washington, D.C.: Urban Areas Division.

Werrell, Kenneth P. (1996) Blankets of Fire: U.S. Bombers over Japan during World War II, Washington: Smithsonian Institution Press. 


\section{Appendix I}

\section{Details on the Construction of Regional Population Data}

Japan has one of the most complete sets of historical regional census data of any country in the world. A major reason why data was collected on a regional level is that while Japan was unified in theory, in practice local lords often had substantial autonomy and Japanese government records reflected this. Until the mid 1870's Japan was divided into 68 provinces or kuni. However one of the kuni, Ezo, now Hokkaido, reported data very erratically due to the low Japanese population and was dropped from our sample. These data were collected as a part of the Japanese tax system envisaged in the Taika reform of 646. However, a series of assassinations, coups, and civil wars delayed full-scale implementation until 702. At that time, cultivators over the age of 6 were allocated land from the government and in return had to pay lump sum in-kind taxes. (Hall p. 54). This forced the government's Popular Affairs Ministry to keep detailed population and tax records many of which exist today.

The raw census data is hard to use, because censuses were done infrequently and often included different standards for covering samurai, non-land holders, women, children, etc. For example, Kii did not report people under the age of 8 while other provinces reported significantly younger children. Over the last 75 years, due in large measure to enormous efforts on the part of Japanese historical demographers, notably Sawada (1927), Sekiyama (1958), and Kito (1999), these data have been carefully organized and rendered systematic. This typically involves incorporating procedures to estimate the missing youth population based on age distributions in neighboring regions.

Our data on regional population between 725 and 1872 is based on Kito (1996). The Kito dataset represents the culmination of these efforts by providing best estimates of the provincial population for $725,800,900$, and 1150 . For these years, data is either based on actual census data where available or on the number of "villages" ( $\mathrm{go}$ ) per province. In the Japanese system used at the time, each "village" or go was comprised of three hamlets containing 50 households per hamlet. Hence, if one can estimate the number of family members per household, based on existing household data in some regions, one can obtain reasonable estimates of the regional population based on the number of "villages".

How well this method works can be assessed by how well these estimates conform to subsequent discoveries of census data. For example, Farris (1984, p. 175) reports that after Sawada (1927) did his original analysis, archaeologists uncovered actual census data for Hitachi province in the year 800, a missing datum in Sawada. Sawada's estimate of 217,000 residents was quite close to the census number of 190,000.

Data for 1600 is based on a major cadastral survey conducted under the order of Shogun Hideyoshi Toyotomi. The frequency of census data increases from 1721 when Japan began to use these censuses as part of their anti-Christian campaign. Unfortunately, there were no regional censuses taken between 1872 and 1920. Although some authors report figures for the intervening years, these are largely interpolations between the two end points.

Another complication arises from the fact that historical regional data is based on 68 provinces whose boundaries do not correspond precisely to the 47 prefectures used in modern census reporting. For example, the province of Musashi was broken up into two prefectures, Tokyo and Saitama. Others are harder to map into modern prefectures - e.g. the province Kii contains all of Wakayama prefecture and part of Mie. Feudal lords in Japan ruled over several 
hundred domains, which, in general did not have boundaries that correspond to provincial boundaries. The borders of these domains changed significantly over the course of the next millennium in response to wars and patronage, but the borders of the provinces did not. We solved this problem by using a historical map provided by Hanley and Yamamura (1977) and comparing it with modern maps. This generates a concordance, which we present in Appendix Table 1 . We then checked our matching by comparing the aggregate area of the provinces [from the 1882 Japanese Imperial Statistical Yearbook] with the areas of corresponding prefectures [from the 1998 Japan Statistical Yearbook]. This suggests that we matched the data quite closely.

We measured regional density as the number of people per square kilometer. One problem that can arise is that regional definitions using provincial data may be slightly different from those using prefectural data. In order to eliminate this problem, we implemented the following procedure. Whenever we formed a region using provincial population data we deflated it with provincial area data. Likewise, whenever we formed a region using prefectural population data, we deflated using prefectural area data.

While there is a very large literature in Japan on the accuracy of historical numbers, most researchers believe that the population numbers, at least from 1721 onwards, are accurate to within 15 percent. The reason that we have a good sense about the accuracy is that in a few cases provincial boundaries and feudal domain boundaries coincided. Sometimes the feudal lord in these areas would conduct an independent population census of his domain, and then we can compare the results of the two surveys. So, for example, in the province of Bizen, central government data puts the 1798 population at 321,221 while the lord of Okayama believed the total to be 320,795 . However, both of these numbers underreport the population of the castle town, which Hanley and Yamamura (1977) suggest would take the total to 342,013. The point, of course, is that while the data from 1721 onwards is far from perfect, the level of measurement error is not so high as to render the data meaningless.

Prior to 725 , it is also possible to obtain estimates of the Japanese population based on archeological evidence. Japan has been populated for at least 10,000 years and there are 28,013 archaeological sites from the Jomon period (-8000 to -300) and another 10,530 sites from the Yayoi period (-300 to 300). Koyama (1978) has divided categorized these sites by prefecture and they can be used to provide a rough idea of the regional distribution of population by prefecture.

\section{Details on Urban Data}

There are two principal sources of information on death and destruction caused by World War II in Japan: the US Strategic Bombing Survey (USSBS) (1947) and Nakamura and Miyazaki (1995). This latter source is basically a reprint of "The Report on Damage and Casualties of World War II" compiled by The Central Economic Stabilization Board (CESB) in 1949. The US source is particularly good for matching death and destruction to particular US air operations, while the Japanese source is a 600-page census of all death and destruction that occurred within Japan proper. As such, the Japanese source provides a more complete record of how the war affected civilians.

Since our primary interest was obtaining information on the magnitude of shocks to cities regardless of the particular air operation that gave rise to it, we felt the Japanese source was more 
appropriate. Japanese numbers for casualties and destruction tend to be larger than the numbers reported above for a number of reasons. First, the USSBS only covers destruction due to planned strategic bombing. It therefore does not include urban deaths due to other bombing activities, strafing, naval bombardments of coastal cities, and the mining of harbors, nor does it cover destruction arising from accidentally bombing the wrong targets. Second, US fatality data appear to be only reported for confirmed deaths. In nuclear bombing and firebombing, it is quite common for thousands, if not tens of thousands of people, to be vaporized. People who went missing on the day of a bombing raid and did not turn up within several years are not countecas casualties in US sources but are listed as missing in CESB and are added to fatality numbers. ${ }^{2}$ Third, US data does not treat mortally injured people as fatalities, whereas Japanese data does. This is particularly a problem in Hiroshima and Nagasaki where large numbers of people died of radiation poisoning within a few years of the attack. This helps explain why the CESB reports twice as many fatalities in Nagasaki as USSBS. A more difficult issue concerns radiationinduced deaths in the period between 1949 and 1965. However, since direct deaths were so large, even high estimates (in the tens of thousands) of the number dying from radiation do not affect our numbers on deaths per capita very much.

Population data were taken from the Kanketsu Showa Kokusei Soran. A key feature of this source is that city areas are held constant across the time period. This data source reports urban populations for several hundred cities based on censuses every five years. ${ }_{3}$ The only exception is 1945. The 1945 census of cities was not performed until 1947 due to the war. This is actually fortunate for us. Japanese ground transportation was largely unaffected by the war. This means that by 1947, anyone who had fled due to the fear of air strikes, could have returned provided that housing and employment existed there.

\footnotetext{
${ }^{22}$ One might worry that the missing category might be capturing something else, but the number of people reported missing in cities not subject to bombing is almost always zero.

${ }^{23} \mathrm{We}$ dropped the city of Kure from our data. Kure became the site of a major Japanese naval arsenal. As a result its population rose 50\% between 1925 and 1940 as Japan built up its fleet. Kure was heavily bombed during the war and then returned to its prewar size as demand for naval warships approached zero.
} 


\section{Appendix Table 1}

\section{Concordance between Provinces and Prefectures}

Province (Kuni)

Iwaki, Iwashiro, Rikuzen, Rikuchu, and Mutsu Uzen-Ugo

Awa1, Kazusa, Shimo-osa

Awa2

Bingo, Aki

Bungo

Chikuzen, Buzen, Chikugo

Echigo, Sado

Etchu

Harima, Tajima, Awaji

Higo

Hitachi

Hizen, Tsushima, Iki

Hyuga

Iga, Ise, Shima

Inaba, Hoki

Iyo

Izumo, Iwami, Oki

Kaga, Noto

Kai

Kawachi, Izumi, Settsu

Kii

Kozuke

Mimasaka, Bizen, Bitchu

Mino, Hida

Musashi

Omi

Osumi, Satsuma

Owari, Mikawa

Sagami

Sanuki

Shimotsuke

Shinano

Suo, Nagato

Tosa

Totomi, Suruga, Izu

Wakasa, Echizen

Yamashiro, Tamba, Tango

Yamato
Prefecture (Ken)

Aomori, Iwate, Miyagi, and Fukushima

Akita, Yamagata

Chiba

Tokushima

Hiroshima

Oita

Fukuoka

Niigata

Toyama

Hyogo

Kumamoto

Ibaraki

Nagasaki-Saga

Miyazaki

Mie

Tottori

Ehime

Shimane

Ishikawa

Yamanashi

Osaka

Wakayama

Gunma

Okayama

Gifu

Tokyo-Saitama

Shiga

Kagoshima

Aichi

Kanagawa

Kagawa

Tochigi

Nagano

Yamaguchi

Kochi

Shizuoka

Fukui

Kyoto

Nara 